\title{
Study of Urinary Tract Infections in Febrile Infants and Children 2 to 24 Months at a Tertiary Care Centre
}

\author{
Vishal Garg ${ }^{1 *}$, Pawan Kumar² \\ ${ }^{1 *}$ Assistant Professor, Department of Pediatrics, Rama Medical College, Hapur, UP, India. \\ ${ }^{2}$ Associate Professor, Department of Pediatrics, Santosh Medical College, Ghaziabad, UP, India.
}

\begin{abstract}
Background: UTI is one of the most common serious bacterial infection in febrile infants and young children and more common than bacterial meningitis, pneumonia and occult bacteraemia. It includes $10 \%$ of all febrile children, $13.6 \%$ of febrile infants and $7 \%$ of febrile newborns. Present study was conducted to estimate the prevalence and etiological factors of UTI among febrile children 2 to 24 Months of age.
\end{abstract}

Methods: A cross-sectional hospital-based study was conducted among 173 children with fever for more than 5 days without localizing signs, between the ages of 2 to 24 Months attending the Paediatric OPD of Rama Medical College, Hapur, UP (India). Those who have $>5$ pus cells in urine analysis, urine culture was done. Children with recurrent UTI were evaluated by abdominal ultrasonogram, MCU and DMSA scan. Results: 43 children showed significant pyuria $(24.9 \%)$ and among them 23 children (53.5\%) showed culture positivity. The overall prevalence rate of urinary tract infection in the present study was $13.3 \%$. Urine culture was positive in $22.9 \%$ and $100 \%$ of children with pus cells $5-10 / \mathrm{HPF}$ and $>10 / \mathrm{HPF}$ respectively. Proportion of UTI is more in uncircumcised male (9.33\%) compared to circumcised male (6.67\%). Among 173 children, Among children with recurrent urinary tract infection, features of pyelonephritis in DMSA scan were present in 3 (33.3\%) children and grade 3 VUR (Reflux into dilated ureter) was present in 1 subject (11.1\%) in MCU and no reflux in rest 5 children (55.5\%).

\section{INTRODUCTION}

Urinary Tract Infection (UTI) is defined by the presence of organisms in the urinary tract, which is usually sterile. However, since asymptomatic colonization of the urinary tract can occur, other features such as the presence of inflammatory markers or follow-up cultures may be needed to definitively diagnose a UTI. ${ }^{1}$ UTI is one of the most common serious bacterial infection in febrile infants and young children and more common than bacterial meningitis, pneumonia and occult bacteraemia. ${ }^{2}$ It includes $10 \%$ of all febrile children, $13.6 \%$ of febrile infants and $7 \%$ of febrile newborns. ${ }^{3}$ About $8 \%$ of girls (3\% pre-pubertal) and $2 \%$ of boys ( $1 \%$ pre-pubertal) experience at least one episode of UTI up to the age of 7 years. ${ }^{4}$

Stephen M. Downs stated in a technical report of American Academy of Pediatrics that the overall problem of managing UTI
Conclusions: UTI is a common pediatric problem with the potential to produce long-term morbidity. Young children presenting with fever may have nonspecific symptoms of UTI, and a high index of suspicion is appropriate in this setting, as bacteriuria would indicate a high probability of upper tract infection. As an initial screening test urinalysis is useful and pus cells count of $>5 / \mathrm{HPF}$ is suggestive of UTI and a count of $>10 / \mathrm{HPF}$ is highly suggestive of UTI and a culture of the urine is required to confirm the diagnosis.

Key Words: Febrile Children, Urinary Tract Infection (UTI), Recurrent UTI. Renal scar.

\section{${ }^{*}$ Correspondence to:}

Dr Vishal Garg,

Assistant Professor,

Department of Pediatrics,

Rama Medical College, Hapur, UP, India.

Article History:

Received: 27-05-2016, Revised: 15-06-2016, Accepted: 19-06-2016

\begin{tabular}{|l|c|}
\hline \multicolumn{2}{|c|}{ Access this article online } \\
\hline $\begin{array}{l}\text { Website: } \\
\text { www.ijmrp.com }\end{array}$ & Quick Response code \\
\hline DOI: & \\
10.21276/ijmrp.2016.2.5.022 & \\
\hline
\end{tabular}

in children between 2 months and 2 years of age was conceptualized as an evidence model. The model depicts the relationships between the steps in the diagnosis and management of UTI. The steps are divided into the following four phases: 1) recognizing the child at risk for UTI, 2) making the diagnosis of UTI, 3) short-term treatment of UTI, and 4) evaluation of the child with UTI for possible urinary tract abnormality.

Phase 1 according to this evidence model represents the recognition of the child at risk for UTI. Age and other clinical features define a prevalence or a priori probability of UTI, determining whether the diagnosis should be pursued. If children at sufficiently high risk for UTI are not identified for diagnostic evaluation, the potential benefit of treatment will be lost. However, children with a sufficiently low likelihood of UTI should be saved 
the cost of diagnosis (and perhaps misdiagnosis) of UTI when the potential for benefit is minimal. ${ }^{5}$

The incidence of UTI is highest in the first year of life for all children (1\%) but decreases substantially among boys after infancy. ${ }^{6}$ Estimates of UTI incidence among infant boys have varied in different populations, likely due to factors such as circumcision, which has been associated with a reduction in risk of UTI. ${ }^{7-9}$

Another issue affecting estimates of incidence is the increased recognition of UTI as a potential source of febrile illness in young children. Screening studies in emergency departments suggest that up to $5 \%$ of children under the age of 2 presenting with fever have UTI, and over half of these would have been given alternative diagnoses such as otitis media had the urine not been screened as part of the study. 10,11

Long-term complications of UTI have been associated with renal scarring and include hypertension, chronic renal failure, and toxemia in pregnancy. Long-term follow-up data are limited, although one Swedish study found that children diagnosed with renal scarring due to pyelonephritis during the 1950s and 1960s developed high rates of hypertension (23\%) and end-stage renal disease (10\%).12 Few studies question the association between pyelonephritis and end-stage renal disease. ${ }^{13,14}$ Although the individual risks associated with UTI remain unclear, the high prevalence of UTI and potential morbidity associated with complications require careful attention to diagnosis and management.

Acute pyelonephritis consists of $2 / 3$ of febrile UTIs in early childhood. ${ }^{2}$ Recent studies using renal parenchyma-avid nuclear scans have revealed that more than $75 \%$ of children under 5 years of age with febrile urinary tract infection have pyelonephritis. ${ }^{15-17}$ Pyelonephritis leads to renal scarring in $27 \%$ to $64 \%$ of children with urinary tract infections in this age group, even in the absence of underlying urinary tract abnormalities. ${ }^{18,19}$ Most urinary tract infections that lead to scarring or diminished kidney growth occur in children younger than 4 years of age, especially in the first year of life. ${ }^{16,19}$ It is essential to identify urinary tract infection in febrile children early and institute prompt treatment to reduce the potential for lifelong morbidity. Therefore, present study was conducted to estimate the prevalence and etiological factors of UTI among febrile children 2 to 24 Months of age.

\section{MATERIALS AND METHODS}

A cross-sectional hospital-based study was conducted among 173 children with fever for more than 5 days without localizing signs, between the ages of 2 to 24 Months attending the Paediatric OPD of Rama Medical College, Hapur, UP (India).

A detailed proforma for collecting data related to age, sex, nutritional status, socioeconomic status (Using Kuppuswamy Socio- economic status scale) and predisposing risk factors like urethral instrumentation, bowel habits, etc. was prepared. Complete history related to the onset of fever, duration associated symptoms such as nausea, vomiting, diarrhea, urinary disturbances and other system involvement was obtained. Thorough physical examination was done in all patients. Routine blood counts, urine analysis were done for all patients and those showing pus cells $>5$ per HPF in centrifuged urine sample were taken as study group and urine culture sensitivity were done. If recurrent UTI ( $\geq 2$ episodes), a thorough physical examination and USG abdomen/renal function test/DMSA/MCU was done for that patient to find out the abnormalities that predispose to recurrent infections. The details of the history, physical examination as well as laboratory findings were entered in the proforma. ${ }^{20}$

Table 1: Distribution of study participants across different age group, sex, socio-demographic and clinical variable

\begin{tabular}{llcc}
\hline Variable & & No. of cases & Percentage \\
\hline Age Groups & 2-6 months & 37 & 21.4 \\
(In Months) & 7th-12 months & 69 & 39.9 \\
& 13th-18 months & 21 & 12.1 \\
Sex & 19th-24 months & 46 & 26.6 \\
& Males & 75 & 43.4 \\
Socio- economic Status & Females & 98 & 56.6 \\
& Upper & 4 & 2.3 \\
& Upper middle & 71 & 41.1 \\
& Lower middle & 85 & 49.1 \\
Previous History of UTI & Upper lower & 13 & 7.5 \\
& No previous history & 157 & 90.8 \\
Congenital Anomalies & Previous history of UTI & 16 & 9.2 \\
& Absent & 171 & 98.8 \\
& Present & 2 & 1.2 \\
& Total & 173 & 100 \\
\hline
\end{tabular}




\section{RESULTS}

Total number of children studied were 173, among them 106 children were below 1 year and 67 above 1 year, 75 were males and 98 were females; 43 children showed significant pyuria $(24.9 \%)$ and among them 23 children (53.5\%) showed culture positivity. The overall prevalence rate of urinary tract infection in the present study was $13.3 \%$. Among culture positive cases, most commonly found organism was E. coli (52.17) followed by Proteus species (17.39\%), Klebsiella (13.04\%), Staphylococci (8.7\%). Urine culture was positive in $22.9 \%$ and $100 \%$ of children with pus cells $5-10 /$ HPF and $>10 /$ HPF respectively.

Proportion of UTI is more in uncircumcised male (9.33\%) compared to circumcised male (6.67\%). Among 173 children, 142 children were having good bladder hygiene (No constipation, no faecal soiling, cleaning the perineum with water and wiping from front to back), 31 were having poor bladder hygiene. Proportions of urinary tract infection were $11.97 \%$ and $19.35 \%$ respectively in good v/s poor bladder hygiene, i.e. higher in those with poor hygiene.

Among 173 children, pinworm infestation was present in 41 and absent in 132. Among children with pinworm infestation 17.07\% were having UTI and among children without pinworm infestation $12.12 \%$ were having UTI.

Among children with recurrent urinary tract infection, features of pyelonephritis in DMSA scan were present in $3(33.3 \%)$ children and grade 3 VUR (Reflux into dilated ureter) was present in 1 subject (11.1\%) in MCU and no reflux in rest 5 children (55.5\%).

\section{DISCUSSION}

Prevalence of UTI in febrile infants in our study, 2-6 months- 6 $(16.2 \%), 7-12$ months-9 $(13.04 \%)$, which is slightly higher in contrast to study conducted by R.K. Kaushal et al. ${ }^{21}$ (2003) who reported prevalence of $8.4 \%$ and $12.3 \%$ in children $<5$ years and infants respectively and lower than Mohammed MTP et al. ${ }^{20}$ who reported prevalence of $18.75 \%$ in children $2-6$ months old \& $14.14 \%$ in $7-12$ months old children. Prevalence of febrile UTI in infants in our study is higher compared to study by Dharni Dharaka et al. ${ }^{22}$ (1993) who reported a prevalence of $5.4 \%$ in febrile infants and Hoberman et al. ${ }^{23}$ (1993) who reported prevalence of $5.3 \%$ in infants and Mohammed MTP et al. ${ }^{20}$ who reported it as $11.3 \%$.

43 children showed significant pyuria (24.9\%) and among them 23 children $(53.5 \%$ of patients showing pyuria) showed culture positivity. Urine culture was positive in $22.9 \%$ and $100 \%$ of children with pus cells 5- 10/HPF and $>10 / \mathrm{HPF}$ respectively. Similar findings were reported by Mohammed MTP et al. ${ }^{20}$ Hence, the presence of pyuria of $>5$ leukocytes/HPF in a centrifuged sample is a significant indicator of UTI.

Proportion of UTI is more in uncircumcised male $(9.33 \%)$ compared to circumcised male $(6.67 \%)$, but the association was not statistically significant. Among 173 children, 142 children were having good bladder hygiene, 31 were having poor bladder hygiene. Proportion of urinary tract infection were $11.97 \%$ and $19.35 \%$ respectively in good v/s poor bladder hygiene, i.e. higher in those with poor hygiene, but both these associations were not statistically significant. Similar findings were reported by Mohammed MTP et al. ${ }^{20}$

Among 173 children, pinworm infestation was present in 41 and absent in 132. Among children with pinworm infestation $17.07 \%$ were having UTI and among children without pinworm infestation $12.12 \%$ were having UTI.

Among children with recurrent urinary tract infection, features of pyelonephritis in DMSA scan were present in 3 (33.3\%) children and grade 3 VUR (Reflux into dilated ureter) was present in 1 subject (11.1\%) in MCU and no reflux in rest 5 children (55.5\%).

According to Chand et al. ${ }^{24}$ primary VUR occurs in less than $1 \%$ of the general population and as many as $50 \%$ of children who present with recurrent UTI will have VUR. But in our study VUR was present in only $11.1 \%$ of children with recurrent UTI.

The question of when to screen for UTI has been evaluated in a number of studies and addressed by a subcommittee of the American Academy of Pediatrics. ${ }^{25}$ The presence of specific symptoms for UTI, including dysuria, frequency, urgency, suprapubic discomfort, and flank pain, should lead to screening. However, young children with UTI may present with nonspecific symptoms, such as poor feeding, vomiting, irritability, jaundice (in newborns), or fever alone, and a broader approach to screening may be appropriate. Two recent studies of the prevalence of UTI among children presenting to an emergency department with fever found rates ranging from 3.5 to $5.5 \% .{ }^{10,11}$ Girls were more than twice as likely as boys to have UTI, and among boys, uncircumcised infants had an eightfold higher risk. This finding compares well with population-based studies of UTI which document a 4- to 10-fold increase in risk of UTI among uncircumcised males during the first year of life, likely due to colonization of the mucosal surface of the foreskin with bacteria. ${ }^{26}$ Other risk factors for UTI among children less than 2 years of age included young age, absence of another source of fever, height of fever, ill appearance, history of UTI, presence of urinary symptoms, and tenderness in the suprapubic area. ${ }^{11}$

\section{CONCLUSION}

UTI is a common pediatric problem with the potential to produce long-term morbidity. Young children presenting with fever may have nonspecific symptoms of UTI, and a high index of suspicion is appropriate in this setting, as bacteriuria would indicate a high probability of upper tract infection. As an initial screening test urinalysis is useful and pus cells count of $>5 / \mathrm{HPF}$ is suggestive of UTI and a count of $>10 / \mathrm{HPF}$ is highly suggestive of UTI and a culture of the urine is required to confirm the diagnosis. Prevalence of culture positivity was $100 \%$ in those who showed $>10$ pus cells/HPF in centrifuged sample of urine. In culture positive UTI, it is always important to do an MCU/DMSA scan to look for VUR and pyelonephritic changes/renal scars, respectively.

\section{REFERENCES}

1. Joseph J. Zorc, Darcie A. Kiddoo and Kathy N. Shaw. Diagnosis and Management of Pediatric Urinary Tract Infections. Clinical Microbiology Reviews, Apr. 2005, 18(2);p. 417-422. doi:10.1128/CMR.18.2.417-422.2005

2. Keren R. Imaging and treatment strategies for children after first urinary tract infection. Curr Opin Pediatr 2007;19(6):705-10.

3. Bauer R, Kogan BA. New developments in the diagnosis and management of paediatric UTIs. Urol Clin North Am 2008;35(1):47-58.

4. Williams GJ, Lee A, Craig JC. Long-term antibiotics for preventing recurrent urinary tract infection in children. Cochrane 
Database Systematic Reviews [internet] 2001;(4):CD001534.

5. Stephen M. Downs. Technical Report: Urinary Tract Infections in Febrile Infants and Young Children. American Academy Of Pediatrics. Pediatrics; April 1999; Vol. 103 No. 4; 1-60.

6. Jakobsson, B., S. H. Jacobson, and K. Hjalmas. 1999. Vesicoureteric reflux and other risk factors for renal damage: identification of high- and low-risk children. Acta Paediatr. Supp. 88:31-39.

7. Bauchner, H., B. Philipp, B. Dashefsky, and J. O. Klein. 1987. Prevalence of bacteriuria in febrile children. Pediatr. Infect. Dis. J. 6:239-242.

8. Wiswell, T. E., and J. D. Roscelli. 1986. Corroborative evidence for the decreased incidence of urinary tract infections in circumcised male infants. Pediatrics 78:96-99.

9. Ginsburg, C. M., and G. H. McCracken, Jr. 1982. Urinary tract infections in young infants. Pediatrics 69:409-412.

10. Hoberman, A., H. P. Chao, D. M. Keller, R. Hickey, H. W. Davis, and D. Ellis. 1993. Prevalence of urinary tract infection in febrile infants. J. Pediatr. 123:17-23.

11. Shaw, K. N., M. Gorelick, K. L. McGowan, N. M. Yakscoe, and J. S. Schwartz. 1998. Prevalence of urinary tract infection in febrile young children in the emergency department. Pediatrics 102:e16.

12. Jacobson, S. H., O. Eklof, C. G. Eriksson, L. E. Lins, B. Tidgren, and J. Winberg. 1989. Development of hypertension and uraemia after pyelonephritis in childhood: 27 year follow up. Br. Med. J. 299:703-706.

13. Esbjorner, E., U. Berg, and S. Hansson. 1997. Epidemiology of chronic renal failure in children: a report from Sweden 19861994. Swedish Pediatric Nephrology Association. Pediatr. Nephrol. 11:438-442.

14. Sreenarasimhaiah, S., and S. Hellerstein. 1998. Urinary tract infections per se do not cause end-stage kidney disease. Pediatr. Nephrol. 12:210-213.

15. Shaw KN, Gorelick MH. Urinary tract infection in the paediatric patient. Paediatric clinics of North America 1999;46(6):1111-23.

16. Benador D, Benador N, Siosman DO, et al. Cortical scintigraphy in the evaluation of renal parenchymal changes in children with pyelonephritis. J pediatr 1994;124:17-20.

17. Majd M, Rushton HG, Jantausch B, et al. Relationship among vesicoureteral reflux, P-fimbriated escherichia coli and, acute pyelonephritis in children with febrile urinary tract infection. $J$ Pediatr 1991;119:578-585.
18. Rushton HG, Majd M, Jantausch B, et al. Renal scarring following reflux and non-reflux pyelonephritis in children: evaluation with $99 \mathrm{~m}$ technetium-dimercaptosuccinic acid scintigraphy. J Urol 1992;147(5):1327-1332.

19. Berg UB. Long term follow-up of renal morphology and function in children with recurrent pyelonephritis. J Urol 1992;148(5 Pt 2):1715-1720.

20. Mohammed MTP, Adarsh U. Prevalence and aetiological factors of urinary tract infection in febrile children 2 months to 2 years. J. Evolution Med. Dent. Sci. 2016;5(22):1140-1142, DOI: 10.14260/jemds/2016/265

21. Kaushal RK, Bansal S, Sharma VK, et al. Urinary tract infection among children presenting with fever. Indian Pediatr 2003;40:269-270.

22. Dharni Dharka VR. Prevalence of bacteriuria in febrile infants. Indian Pediatrics 1993;30:981-986.

23. Hoberman A, Chao HP, Keller DM, et al. Prevalence of urinarytract infection in febrile infants. J pediatr1993;123(1):17-23.

24. Chand DH, Rhoades T, Poe SA, et al. Incidence and severity of vesicoureteral reflux in children related to age, gender, race and diagnosis. J Urol 2003;170(4 t2):1548-50.

25. 1999. Practice parameter: the diagnosis, treatment, and evaluation of the initial urinary tract infection in febrile infants and young children. American Academy of Pediatrics. Committee on Quality Improvement. Subcommittee on Urinary Tract Infection. Pediatrics 103:843-852.

26. 1999. Circumcision policy statement. American Academy of Pediatrics Task Force on Circumcision. Pediatrics 103:686-693.

\section{Source of Support: Nil. Conflict of Interest: None Declared.}

Copyright: (c) the author(s) and publisher. IJMRP is an official publication of Ibn Sina Academy of Medieval Medicine \& Sciences, registered in 2001 under Indian Trusts Act, 1882.

This is an open access article distributed under the terms of the Creative Commons Attribution Non-commercial License, which permits unrestricted non-commercial use, distribution, and reproduction in any medium, provided the original work is properly cited.

Cite this article as: Vishal Garg and Pawan Kumar. Study of Urinary Tract Infections in Febrile Infants and Children 2 to 24 Months at a Tertiary Care Centre. Int J Med Res Prof. 2016; 2(5):113-16 